Support information

\title{
4D Printing of Liquid Crystal Elastomer with Controllable Orientation Gradient
}

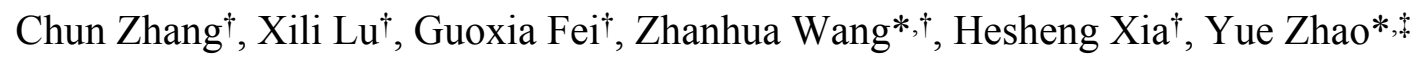

†State Key Laboratory of Polymer Materials Engineering, Polymer Research Institute,

Sichuan University, Chengdu, 610065, China.

Email: zhwangpoly@,scu.edu.cn

‡Département de chimie Université de Sherbrooke Sherbrooke, Québec J1K 2R1, Canada.

E-mail: yue.zhao@usherbrooke.ca 

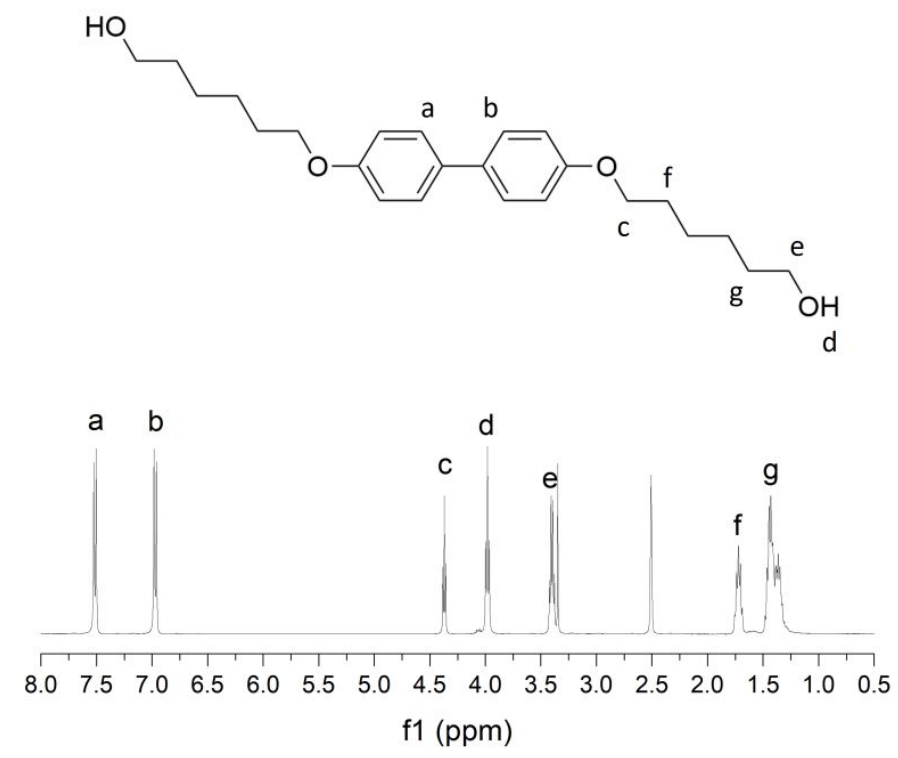

Figure S1. ${ }^{1} \mathrm{H}$ NMR spectrum of 4, 4'-bis(6-hydroxyhexyloxy)biphenyl (BHBBP) in DMSO-d $6 .{ }^{1} \mathrm{H}$ NMR (400 $\mathrm{MHz}, \mathrm{CDCl}_{3}$, TMS): d (ppm) =7.52-7.50 (d, 4H, Ar-Ar), 6.98-6.96 (d, 4H, Ar-O), 4.38-4.36 (t, 4H, Ar-O-CH $)$, 3.99-3.96 (t, 2H, - OH), 3.42-3.37 (m, 4H, $\left.-\mathrm{CH}_{2}-\mathrm{O}\right), 1.75-1.68$ (m, 4H, Ar-O- $\left.\mathrm{CH}_{2}-\mathrm{CH}_{2}\right), 1.48-1.35$ (m, 12H, $\left.\mathrm{Ar}-\mathrm{O}-\mathrm{CH}_{2}-\mathrm{CH}_{2}-\left(\mathrm{CH}_{2}\right)_{3}-\mathrm{CH}_{2} \mathrm{OH}\right)$.
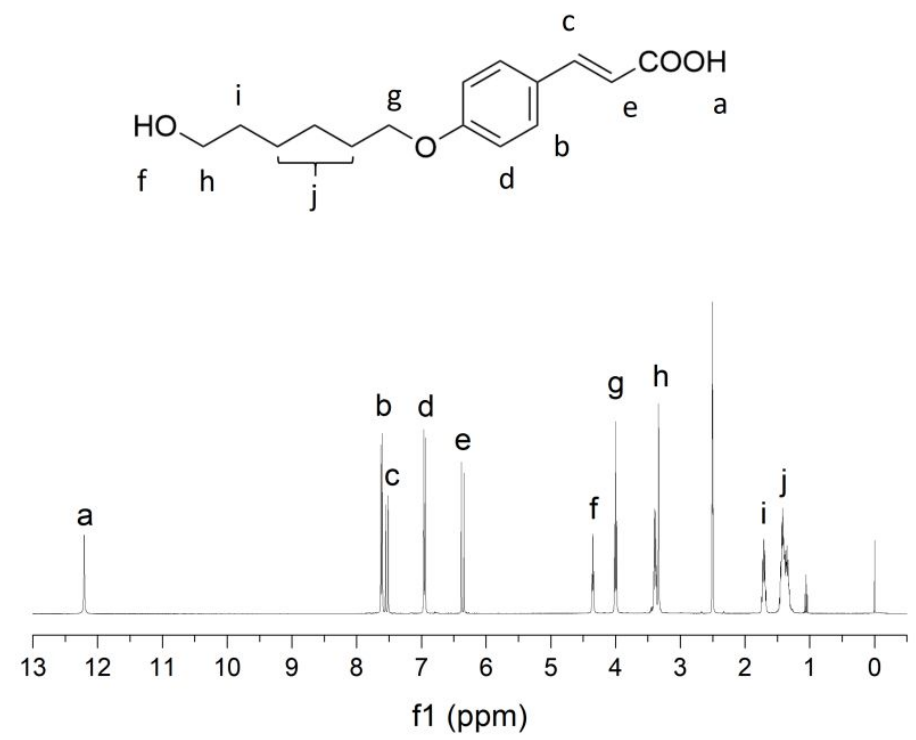

Figure S2. ${ }^{1} \mathrm{H}$ NMR spectrum of 4-(6-Hydroxyhexyloxy)cinnamic acid (6HCA) in DMSO-d $6 .{ }^{1} \mathrm{H}$ NMR (300 MHz, DMSO, TMS): $\delta(\mathrm{ppm})=12.22(\mathrm{~s}, 1 \mathrm{H}, \mathrm{CH}=\mathrm{CH}-\mathrm{COOH}), 7.63-7.61(\mathrm{~d}, 2 \mathrm{H}, \mathrm{Ar}-\mathrm{CH}=\mathrm{C}), 7.56-7.52(\mathrm{~d}, 1 \mathrm{H}$, $\mathrm{Ar}-\mathrm{CH}=\mathrm{C}), 6.96-6.94$ (d, 2H, Ar-O), 6.38-6.35 (d, 1H, CH-COO), 4.36 (s, H, -OH), 4.02-3.98 (t, 2H, Ar-O-CH $)$, 3.40-3.38 (d, 2H, - $\left.\mathrm{CH}_{2}-\mathrm{O}\right), 3.99-3.96$ (t, $\left.2 \mathrm{H},-\mathrm{OH}\right), 1.73-1.69$ (t, 2H, Ar-O-CH $\left.2-\mathrm{CH}_{2}\right), 1.48-1.30$ (m, 6H, Ar- $\left.-\mathrm{O}-\mathrm{CH}_{2}-\mathrm{CH}_{2}-\left(\mathrm{CH}_{2}\right)_{3}-\mathrm{CH}_{2} \mathrm{OH}\right)$. 


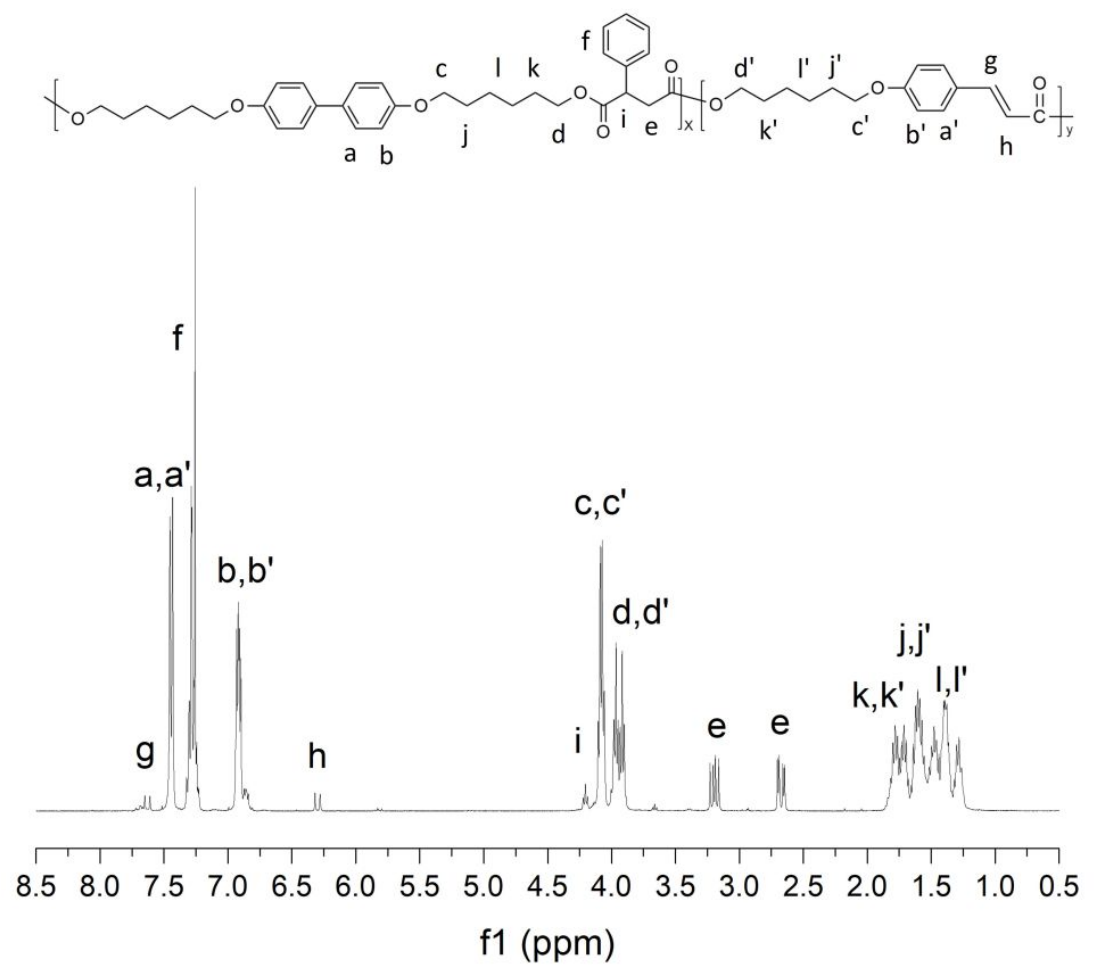

Figure S3. ${ }^{1} \mathrm{H}$ NMR spectrum of liquid crystalline polymer ink in $\mathrm{CDCl}_{3}$.
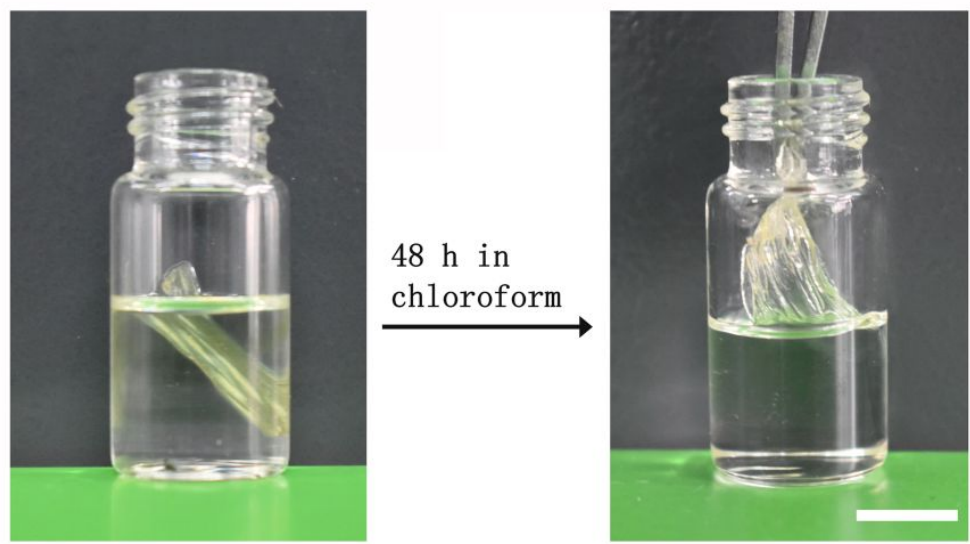

Figure S4. Swelling experiment indicated the fully photocrosslinking. The printed sample was exposed to UV light at an intensity of $80 \mathrm{~mW} / \mathrm{cm}^{2}$ for $1.5 \mathrm{~h}$ for each side. After immersed in the solvent (Chloroform) for $48 \mathrm{~h}$, the sample was swollen and insoluble. Scale bar: $10 \mathrm{~mm}$. 


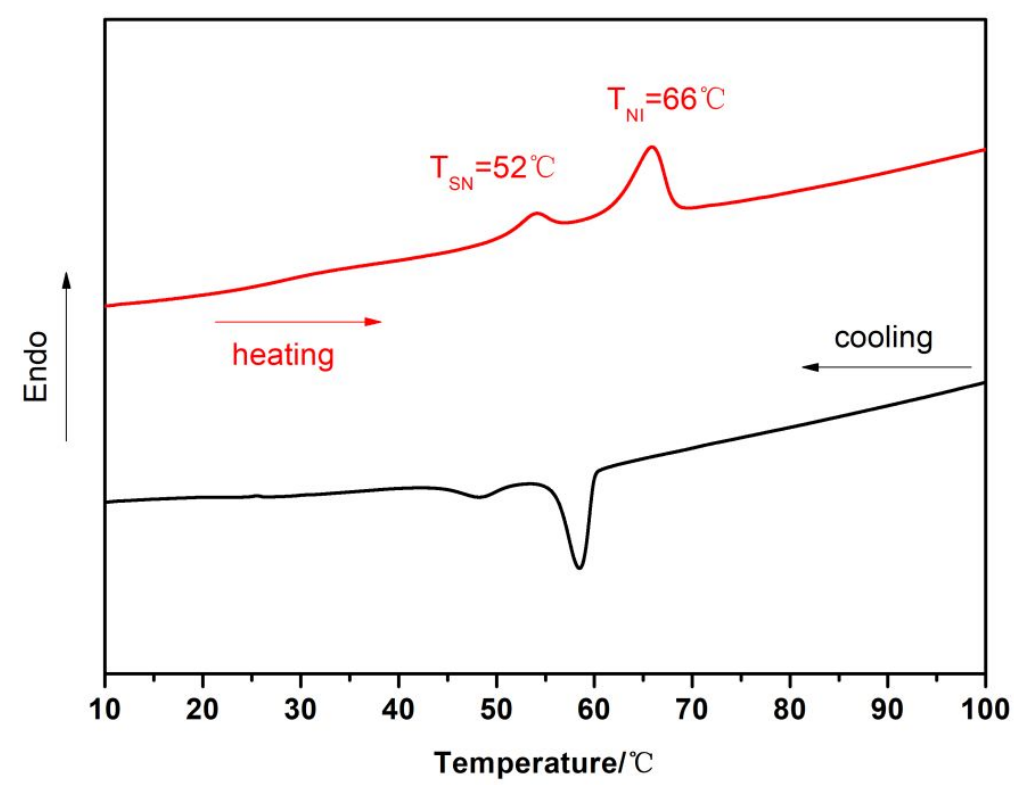

Figure S5. Representative DSC curves of cycle of cooling and heating for the LC ink.

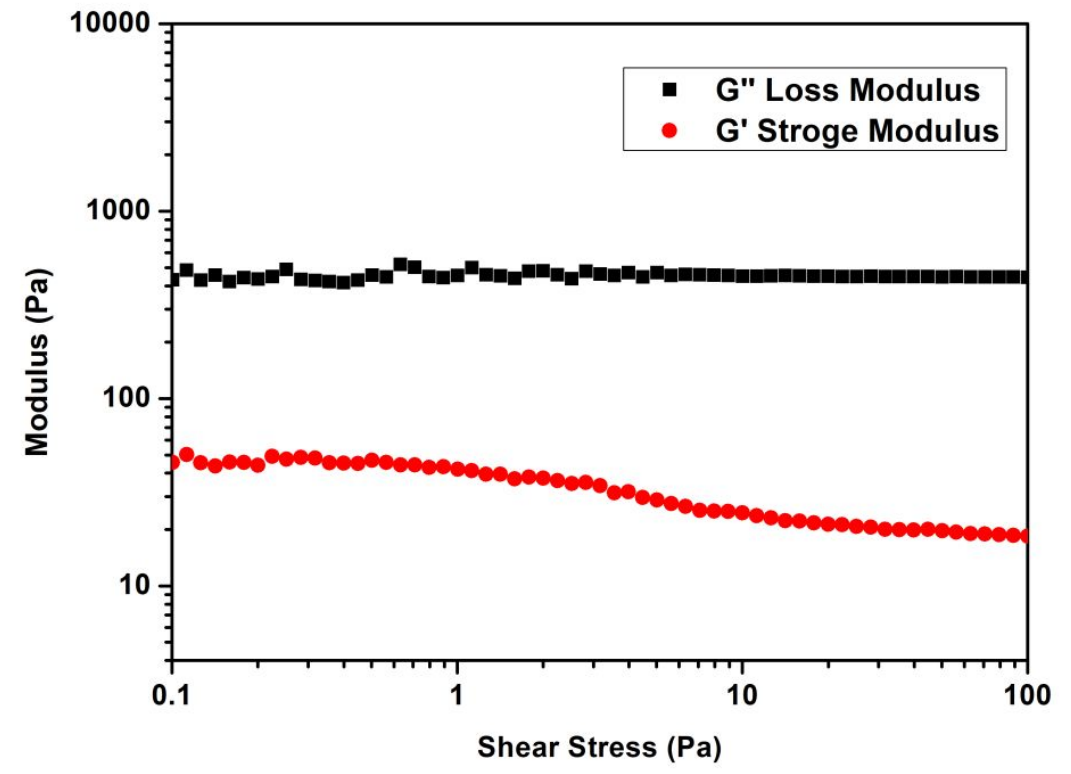

Figure S6. Log-log plot of the shear storage and loss moduli as a function of shear stress for the LCE ink at printing temperature $\left(200^{\circ} \mathrm{C}\right)$. 


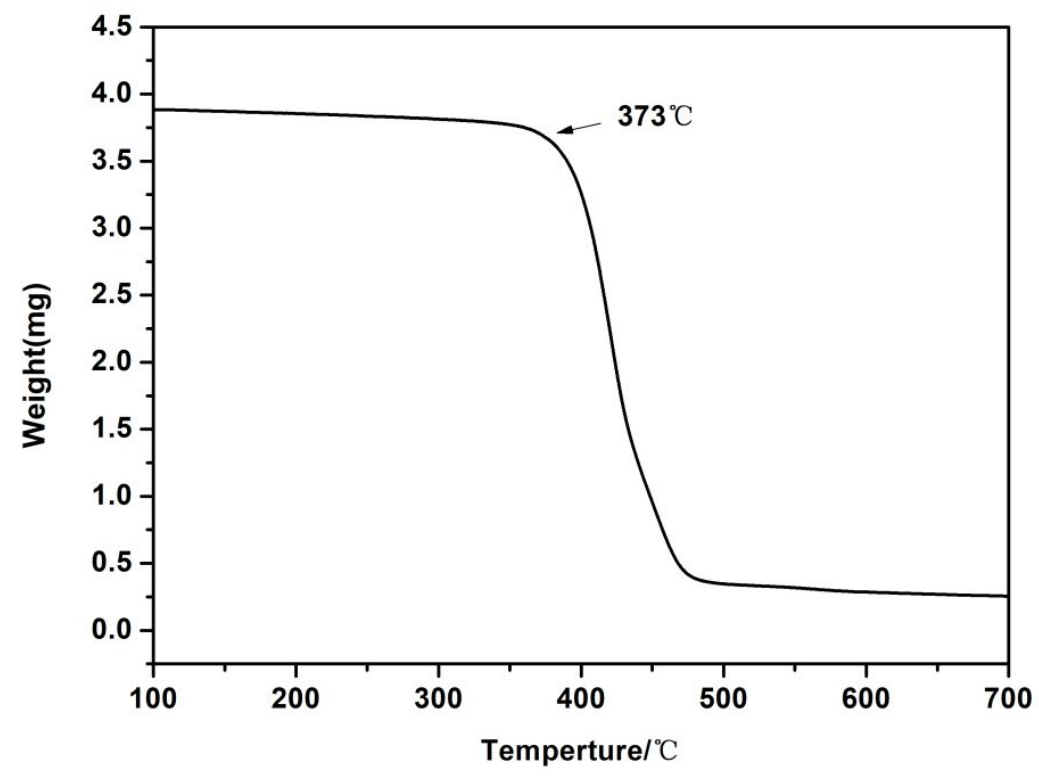

Figure S7. Thermal weight loss analysis of the LC ink, $5 \%$ weight loss at $373{ }^{\circ} \mathrm{C}$.
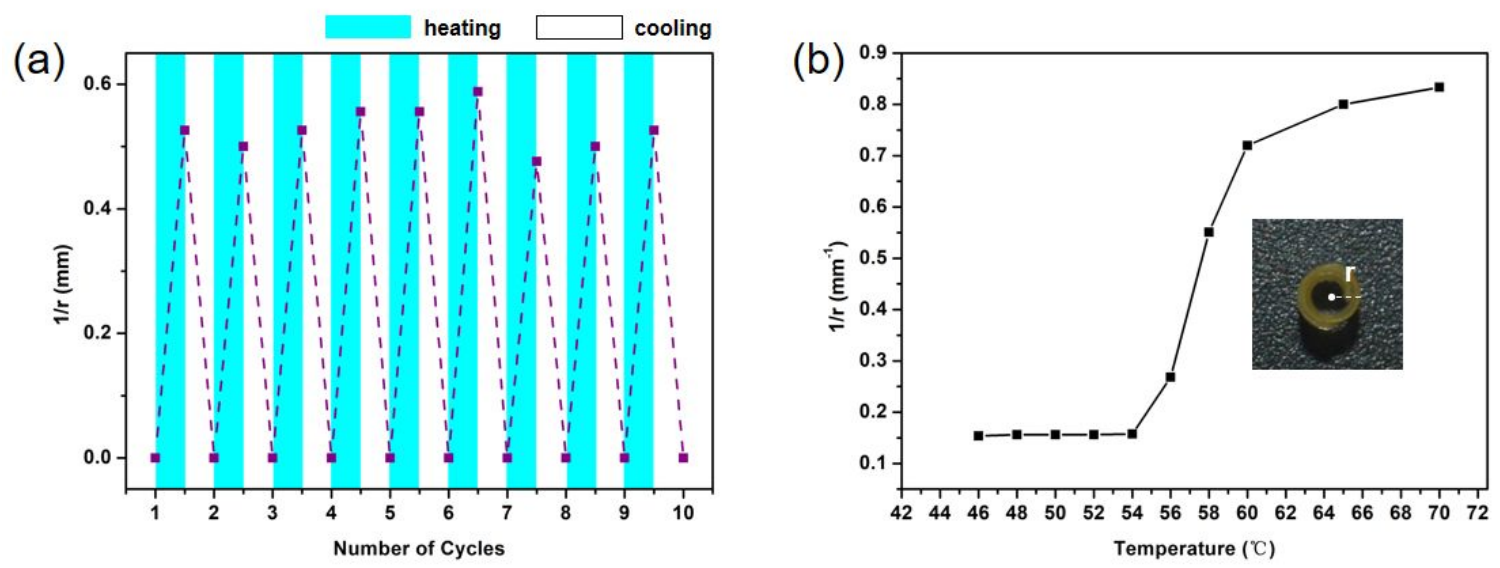

Figure S8. (a) Reversible actuation behaviors of printed sample upon cycling above and below $\mathrm{T}_{\mathrm{NI}}$ for 10 times.

(b) Cylindrical radius changes with temperature. 

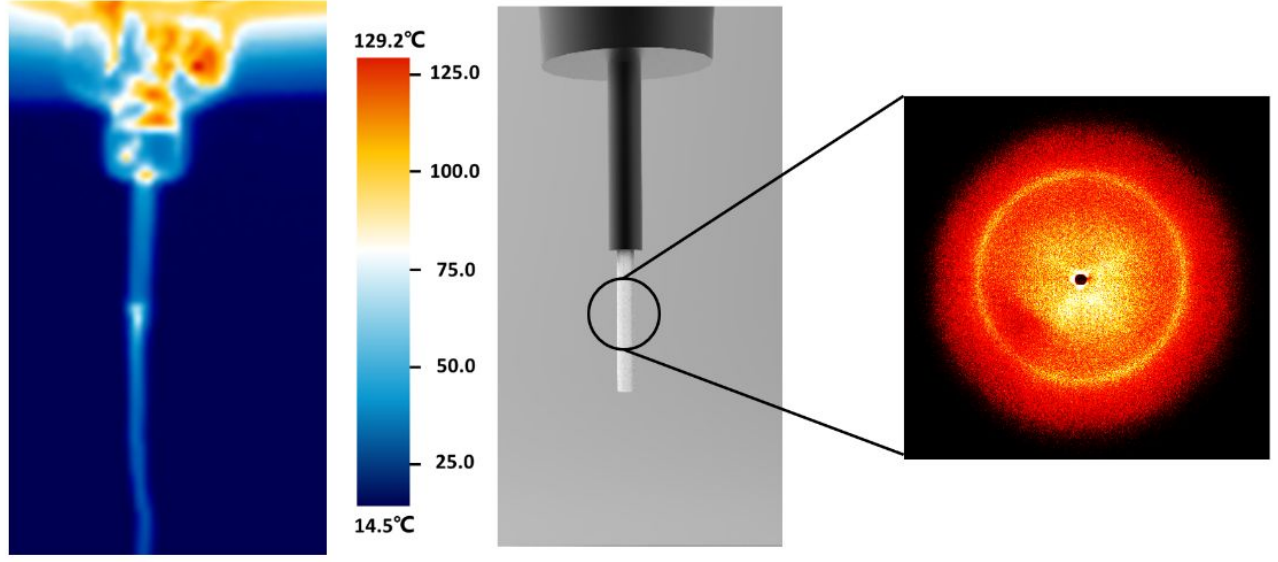

Figure S9. Infrared thermography and corresponding 2D-XRD pattern of the filament extruded from nozzle.

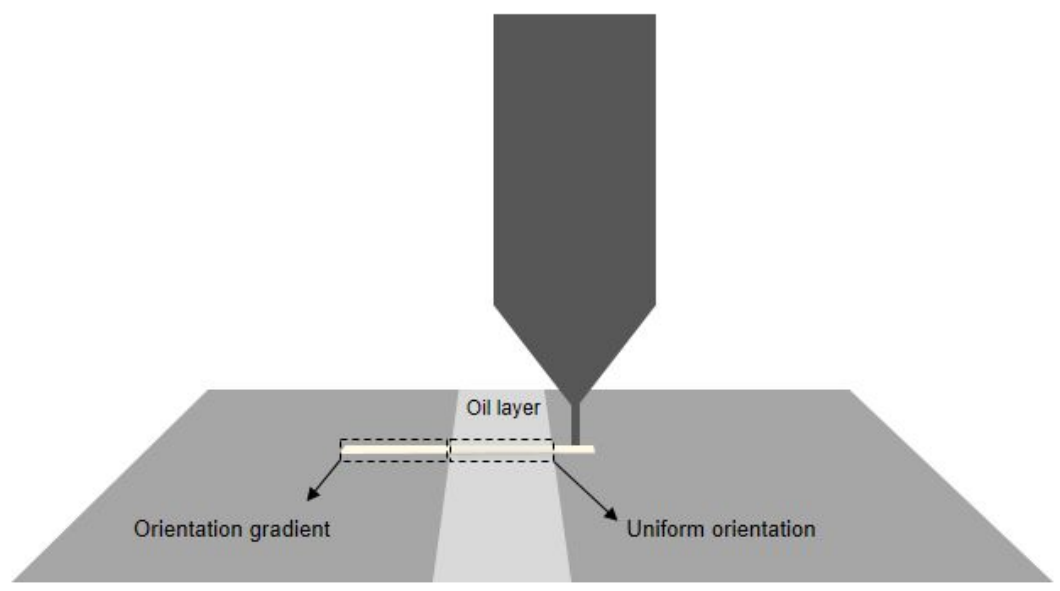

Figure S10. Schematic illustration of the liquid-assistant printing process. 

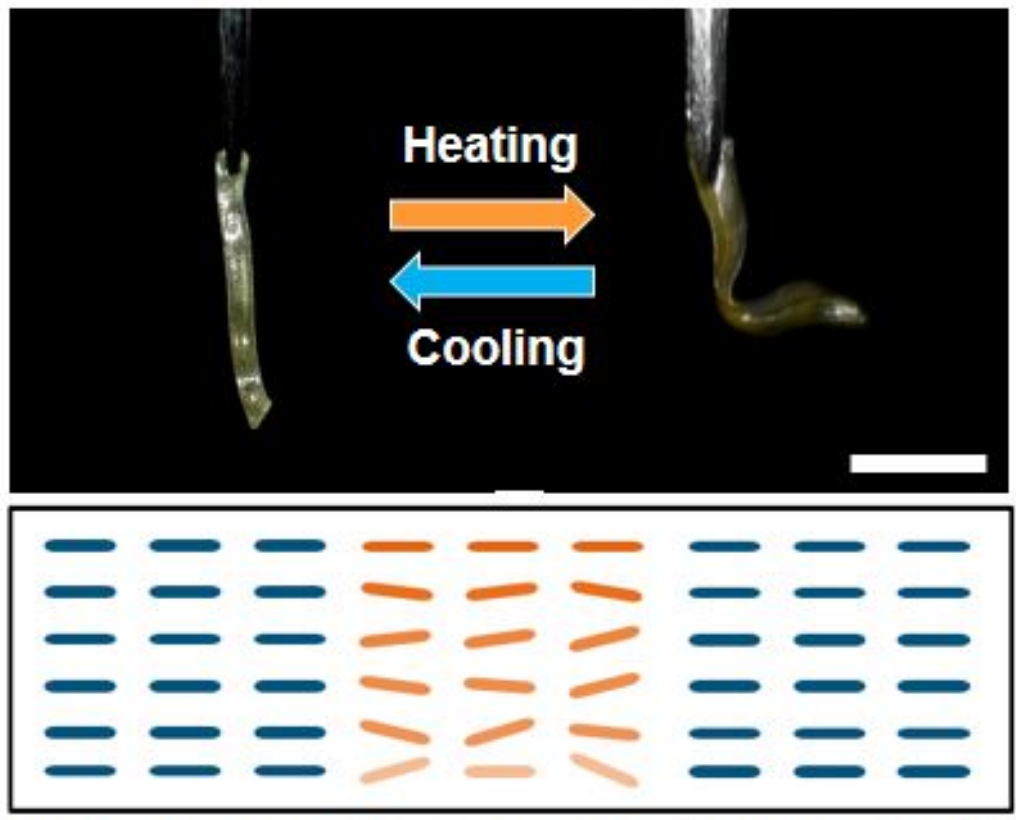

Contraction domain Bending domain Contraction domain

Figure S11. "U" type deformation contains contraction in the two ends and bending in the middle. Scale bar: 10 $\mathrm{mm}$.

(a)

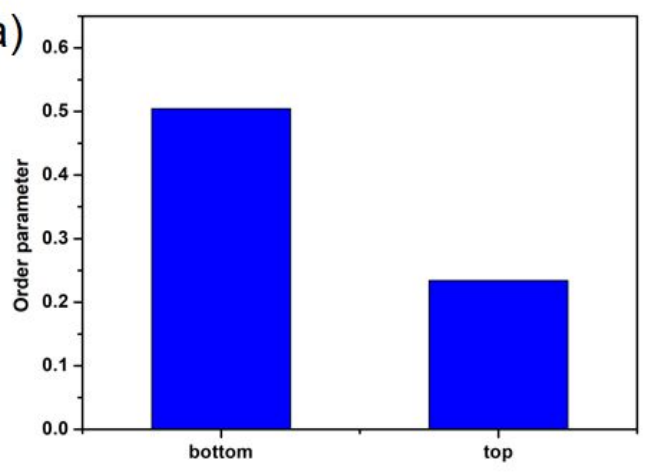

(b)

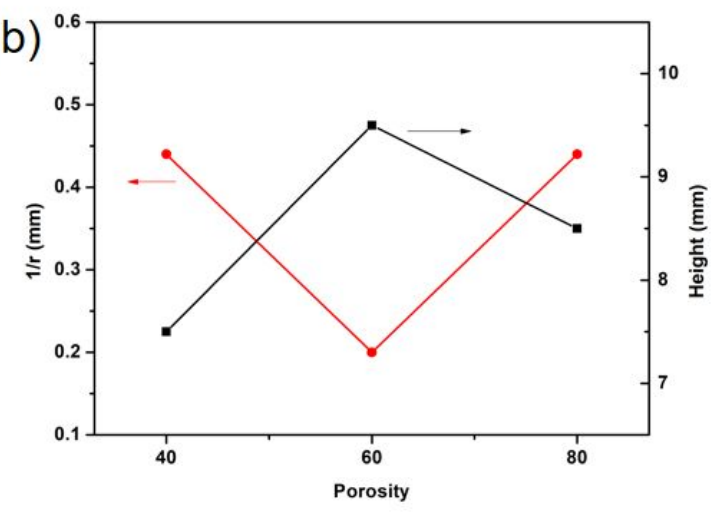

Figure S12. (a) Orientation parameters of bottom and top layer of two-layer porous structure. (b) Effect of different packing densities on deformation radius and height of two-layer porous structure. 